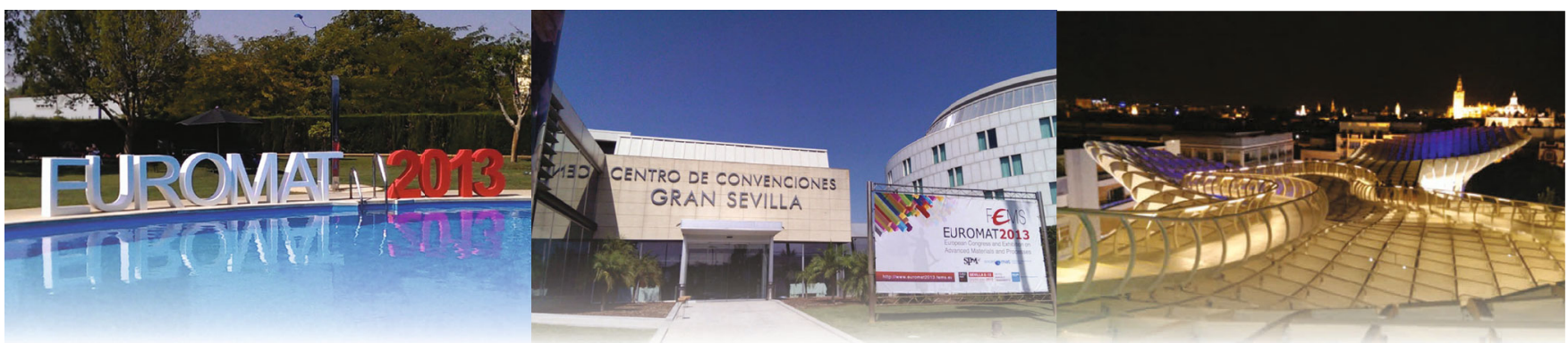

\title{
A World of Possibilities: A Report on the TMS Young Leader International Scholar Program
}

\section{Amy Clarke}

Editor's Note: Amy Clarke, Los Alamos National Laboratory, was the first TMS member chosen to participate in the joint program initiated in 2013 between the Federation of European Materials Societies (FEMS) and TMS to promote international collaboration among young scholars. This joins TMS's long-established international scholar program offered with the Japan Institute of Metals (JIM). For additional information and an application for the TMS Young Leaders International Scholar program, visit the TMS Professional Honors and Awards website at awards tms.org. The TMS Young Leaders International Scholar program is made possible through the support of the TMS Foundation, www.TMSFoundation.org.

It was truly a privilege to be selected as the 2013 Federation of European Materials Societies (FEMS)/TMS Young Leader International Scholar. This award provided me with the unique opportunity to attend the five-day European Congress and Exhibition on Advanced Materials and Processes (EUROMAT) for the first time. EUROMAT was held September 8-13, 2013 at the Hotel Barceló Renacimiento in Sevilla, Spain. The experience enabled invaluable technical exchanges and networking opportunities with colleagues, collaborators, students, and friends, both old and new, and visits to research laboratories in Spain. I am thankful to FEMS and TMS for making the exchange of young professionals to different countries possible.

Similar to the TMS Annual Meeting and Exhibition, a broad range of areas relevant to materials were covered during EUROMAT 2013, including: functional materials; structural materials; materials processing; materials characterization and modeling; materials for energy and the environment; biomaterials and materials for healthcare; and materials education, strategy, and technology transfer.

I am currently an early career scientist at Los Alamos National Laboratory (LANL) in the Metallurgy Group of the Materials Science and Technology Division and am particularly interested in innovative materials processing, structure and property development, and characterization. I gave two talks at EUROMAT 2013 in the advanced metals area. One talk, "Direct Interrogation of Metallic Alloys During Melting and Solidification" highlighted realtime x-ray and proton imaging of metallic alloys during processing. This work utilizes the Advanced Photon Source, a user facility operated for the U.S. Department of Energy (DOE) Office of Science by Argonne National Laboratory, or $800 \mathrm{MeV}$ Proton Radiography (pRad) at LANL. This research is supported by a fiveyear, early career award from the U.S. DOE, Office of Basic Energy Sciences, Division of Materials Sciences and Engineering.

My other talk was "Atom Probe Tomography Examination of Carbon and Alloying Elements in Quench and Tempered Steel." This work was performed

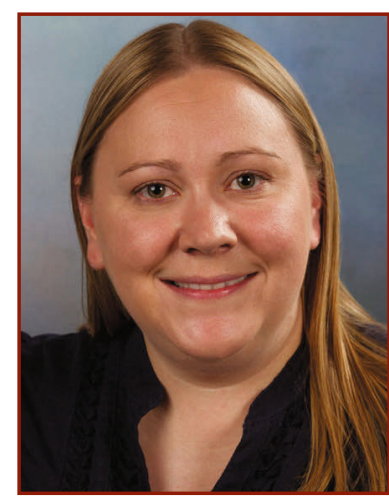

Amy Clarke

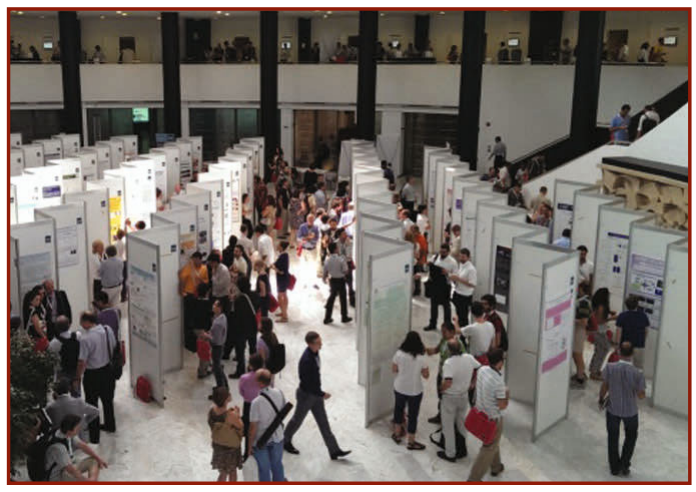

A EUROMAT 2013 poster session at the Hotel Barceló Renacimiento, Sevilla, Spain. 
The author thanks the

following individuals

for making the

FEMS/TMS Young

Leader International

program an enjoyable

and positive

experience: Pedro

D. Portella, FEMS

EUROMAT Scientific

Committee, from the

Bundesanstalt für

Materialforschung

und Prüfung, Berlin,

Germany; Paloma

Fernández, FEMS

EUROMAT Scientific

and Managing

Committees, from

the University

Complutense of

Madrid, Spain;

Agustín Rodríguez

González-Elipe,

FEMS EUROMAT

Scientific Committee,

from the Instituto

de Ciencia de

Materials de Seville,

Spain; Francisca

Caballero, Juan J.

de Damborenea, and

Carlos Capdevila

Montes from the

Centro Nacional

de Investigaciones

Metalúrgicas, Madrid,

Spain; and Debby

Price and the TMS

Foundation. in collaboration with Michael Miller at Oak Ridge National Laboratory, with research at the ShaRE User Facility sponsored by the U.S. DOE, Office of Basic Energy Sciences, Scientific User Facilities Division.

Following EUROMAT 2013, I visited the Instituto de Ciencia de Materials de Seville, Consejo Superior de Investigaciones Científicas (CSIC) in Sevilla, Spain. My host was Agustín Rodríguez GonzálezElipe, the leader of the nanotechnology on surfaces research group on thin film engineering and plasma technology. I met with faculty and staff to discuss research interests and projects and enjoyed a tour of the laboratory facilities, focused on thin film and structure growth and in-house characterization capabilities. I also visited the Centro Nacional de Investigaciones Metalúrgicas (CENIM-CSIC) in Madrid, Spain over the course of two days. My hosts were Francisca Caballero, Juan J. de Damborenea, and Carlos Capdevila Montes. At CENIM-CSIC I gave a seminar, "Multi-Scale and In-Situ Characterization of Phase Transformations in Metals." I also had the opportunity to meet with numerous scientists, staff, and students and took laboratory tours highlighting a variety of materials processing, deformation, characterization, and corrosion capabilities. A partial day was also reserved for students to give short seminars in English about their research and receive feedback from the audience, which was a great, interactive experience for everyone involved. Through these visits, I received a glimpse into the research activities of two CSIC research centers focused on materials and metallurgy, but I was also surprised to learn that this institution is dedicated to scientific research over a broad range of disciplines ranging from humanities and social sciences, to materials science and technology and beyond.

During my visit to Spain, I also had the opportunity to be a tourist and see some sights. While in Sevilla during EUROMAT 2013, I ate a lot of tapas in local restaurants, visited places such as the Sevilla Cathedral and the Royal Alcázar Palace that features many different architectural styles and gardens. With Caballero and Montes from CENIM-CSIC, I had the opportunity to explore Madrid,

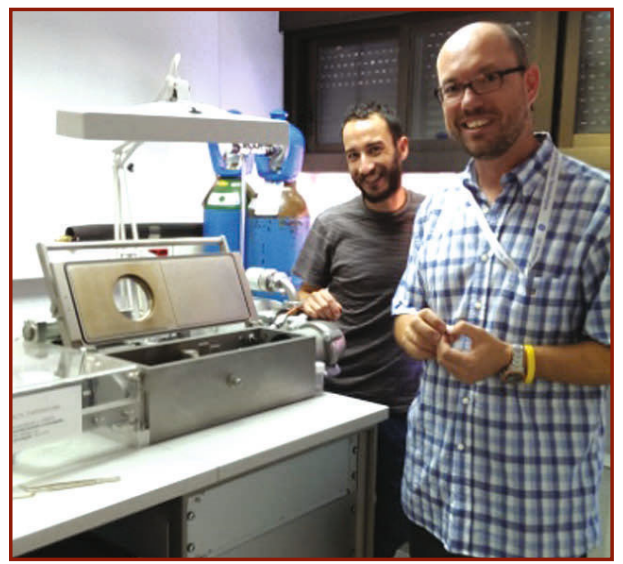

Ruiz Oliva (left) and Carlos Capdevila Montes during a laboratory tour highlighting their dilatometer for studying phase transformations in metals and alloys on heating and cooling.

Segovia, and the surrounding areas, and visited many museums, cathedrals, and palaces. Parts of the landscape and climate near Madrid sometimes reminded me of the U.S. southwest and northern New Mexico, which was a surprising contrast to the more tropical climate of Sevilla.

I had an unforgettable experience in Spain, which was made possible by the FEMS/TMS Young Leaders International Scholar Award and societies such as FEMS, TMS, and JIM that support activities like this, as well as my fantastic and accommodating hosts, collaborators, colleagues, and friends. Visiting Japan in 2010 through the JIM/TMS Young Leader International Scholar Award and receiving a 2008 TMS Young Leader Professional Development Award from the Materials Processing and Manufacturing Division (MPMD) have also been career enhancing, rewarding experiences. I continue to meet new people and am now more actively involved in leadership roles within TMS, serving as the Phase Transformations Committee chair and the Membership and Student Development Committee vice chair. I am also a member of the Solidification and the Young Professionals Committees. I strongly encourage all young professionals to take advantage of these amazing opportunities and to become more involved in promoting TMS around the world.

Amy Clarke is a scientist at Los Alamos National Laboratory. 